\title{
Effect of Nursing Instructions on Knowledge and Practice of Mothers Having Children with Leukemia Undergoing Chemotherapy
}

\author{
TAHA M. TAHA, M.Sc.*; SOHEIR A. MOHAMED, D.Sc.*; NAGLAA F. MAHMOUD, D.Sc.* and \\ WAEL Z. KHALID, M.D.** \\ The Department of Pediatric Nursing, Faculty of Nursing* and The Department of Pediatric Oncology, \\ National Cancer Institute**, Cairo University, Egypt
}

\begin{abstract}
Background: Acute Lymphoblastic Leukemia (ALL) is the most common malignancy encountered at the pediatric age group.

Aim of Study: Was to evaluate the effect of nursing instructions on knowledge and practice of mothers having children with leukemia undergoing chemotherapy.

Subjects and Methods: One group pre-posttest design quasi-experimental research design was utilized to carry out the current study. The current study was conducted in Pediatric Oncology Outpatient Clinic and Inpatient Department at National Cancer Institute (NCI), Cairo University. A convenient sample of 50 mothers of children with ALL undergoing chemotherapy was participated for the current study. Data were collected using the following tools, structured interview questionnaire; knowledge assessment sheet and reportedpractice sheet.
\end{abstract}

Results: The results of the study revealed that there were statistically significant differences between mothers' total mean scores of knowledge and reported practice after than before receiving nursing instructions. All mothers had poor level of knowledge and reported practice regarding care of their children with leukemia undergoing chemotherapy before getting nursing instructions. After receiving nursing instructions, the highest percentage of them had average level of reported practice and good level of knowledge.

Conclusion: The study concluded that the designed nursing instructions were effective in improving mothers' knowledge and reported practice regarding care of their children with leukemia undergoing chemotherapy.

Recommendation: The study recommended the integration of the designed nursing instructions for mothers in Pediatric Oncology Units; it would provide a framework for mothers' role for their children with leukemia.

Key Words: Nursing instructions - Childhood leukemiaChemotherapy - Mothers' knowledge and practice.

Correspondence to: Dr. Taha M. Taha, The Department of Pediatric Nursing, Faculty of Nursing, Cairo University, Egypt

\section{Introduction}

CANCER is a generic term for a large group of diseases that can affect any part of the body. Other terms used are malignant tumors and neoplasms. One defining feature of cancer is the rapid creation of abnormal cells that grow beyond their usual boundaries, and which can then invade adjoining parts of the body and spread to other organs, the latter process is referred to as metastasizing. Metastases are the major cause of death from cancer [1]

In high-income countries, the annual incidence of childhood cancer is approximately 140 per 1 million children younger than 15 years old, although estimates vary between and within countries. Incidence rate from low and middle income country registries are generally significantly lower, as annual rate per 1 million children of 45.6 in Namibia and 64.4 in India, respectively. Some of this variation may relate to differences in environmental exposures or to biologic susceptibility [2] However, [3] estimated that the 5-year survival rate for all cancers in children is $80 \%$. In addition, National Cancer Institute, in United States of America [USA] (2017) estimated that, 10,270 new cases of cancer will be diagnosed among children from birth to 14 years, and about 1,190 children are expected to die from the disease. Although, pediatric cancer death rates have declined by nearly 70 percent over the past four decades, cancer remains the leading cause of death from disease among children.

Acute Lymphoblastic Leukemia (ALL) is the most common malignancy encountered at the pediatric age group, one in four cancerous children is affected with ALL in the USA. Although survival 
rates for childhood ALL have improved significantly over the past 50 years, so that the existing 5year survival rate in developed countries exceeds $85 \%$, a substantial number of children and adolescents continue to relapse, greatly increasing the risk of mortality. Results of ALL treatment in developing countries have been inferior to those obtained in developed countries, even if the same protocols were used [4]

Improvement in the 5-year survival rate for ALL in children continue to be seen. The 5-year survival for patients with ALL was $84 \%$ for children and young adults less than 19 years of age and $88 \%$ for children and teens less than 15 years of age. Multiple factors have contributed to this improvement, including a better understanding of the immunobiology of ALL and disease burden, use of effective drugs and intensification of treatment, delineation of prognostic factors with risk-adapted treatment and improvements in supportive care.

Chemotherapy is the main treatment for nearly all childhood leukemia. This is treatment with anticancer drugs that are given into a vein, into a muscle, into the Cerebrospinal Fluid (CSF), chemo drugs enter the bloodstream and reach all areas of the body, making this treatment very useful for cancers such as leukemia. Generally, treatment of leukemia uses combinations of several chemo drugs. Chemo in cycles, with each period of treatment followed by a rest period to give the body time to recover. In general, treatment for Acute Myeloid Leukemia (AML) uses higher doses of chemo over a shorter period of time (usually less than a year), and ALL treatment uses lower doses of chemo over a longer period of time (usually 2 to 3 years) [6]

Tariman, et al., [7] emphasized that information giving has been an essential part of the nurse's role in clinical practice. Supported nurse's role of information giving to parents related to various types of therapy and tests. In the palliative care setting, nurses are vital in providing information related to disease and nurses shared that they have to balance clinical decision making based on the patient and family preferences and wishes. Parents' information giving by nurses is well studied in the population of children with cancer. Nurses play a major role in the provision of disease-and treatmentrelated information, as well follow-up of chemotherapy protocol adherence.

\section{Significance of the study:}

Leukemia is the most common childhood malignancies constitutes $33.2 \%$ of all childhood ma- lignancies, those children represent $73,3 \%$ of all pediatric patients with leukemia at Nasser Institute, Egypt [8,9]. Recommended that treatment outcome could be improved by interventions that help to prevent abandonment of therapy such as support groups and educational programs for families and nurses.

The diagnosis of leukaemia has an immediate and lasting impact on child and family. It represents a major challenge to the family, as well as to the child, families must endure the transition from feeling in control of their lives to living with constant uncertainty. These transition need effective preparation by providing them with full explanation about the disease, diagnostic procedures, treatment and its associated side effects, the purposes and expected benefits of the treatments, common morbidities from procedures and instructing them to engage in their child's care.

It has been observed during the researcher's experience as a clinical instructor that children with leukemia undergoing chemotherapy were at high risk for many complications related to the lack of awareness and inadequate training of the mothers of these children which appeared with ineffective adaptive coping skills, inappropriate care which resulting in undesirable outcomes.

In Egypt, there are scarce researches conducted to investigate the effect of nursing instructions on chemotherapy outcomes in nursing branches especially in pediatric nursing. So, the current study investigated the effect of nursing instructions for the mothers having children with leukemia undergoing chemotherapy this hopefully set a standard care that can be followed to improve the knowledge and practice of these mothers and achieve better outcomes for their children. Also it is hoped that findings of this study would be helpful in assuring quality of care and providing evidenced based data that can develop nursing practice and research in the field of pediatric oncology nursing.

\section{Aim of the study:}

The aim of the current study was to evaluate the effect nursing instructions on knowledge and practice of mothers having children with leukemia undergoing chemotherapy.

\section{Hypotheses:}

1- Mothers having children with leukemia who receive the nursing instructions will have higher knowledge scores about care of children with leukemia undergoing chemotherapy than before. 
2- Mothers having children with leukemia who receive the nursing instructions will have higher reported practice scores about care of children with leukemia undergoing chemotherapy than before.

\section{Subjects and Methods}

\section{Research design:}

One group pre-posttest design quasi-experimental research design was utilized to fit this study. The group was treated as a study group and its own control group at the same time.

\section{Setting:}

The current study was conducted in Pediatric Oncology Outpatient Clinic and Inpatient Department at National Cancer Institute (NCI), Cairo University.

\section{Study subjects:}

A convenient sample of 50 mothers of children with ALL undergoing chemotherapy who attended the mentioned settings and fulfilled the inclusion criteria has been participated in the current study.

\section{Inclusion criteria:}

A- Children:

- Age from 3-15 years.

- Both genders.

- Children diagnosed with ALL during the diagnosis period till the end of induction phase of chemotherapy and free from chronic illness such as diabetes, kidney diseases ....etc. or other types of malignancies.

- Children who were during.

\section{B- Mothers:}

- All mothers who accepted to participate in the current study regardless their age or level of education.

- Mothers who had no other children with leukemia or any cancer patients receiving chemotherapy.

\section{Tools for data collection:}

The required data were collected through the following tools which developed by the research investigator after extensive review of related literature:

1- Structured interview questionnaire: It contained 30 questions and it was divided into two parts:

Part I:It involved 13 questions to collect the personal data related to the mothers e.g. age, education, presence of consanguinity, occupation, family income, number of children, etc It also was included data related to the children' characteristics e.g. age, gender, rank, school enrollment, etc....

Part II: It contained 17 questions about the child's disease history e.g. diagnosis, date of admission, signs and symptoms, etc...

2- Knowledge assessment sheet: It contained 32 questions, it was developed to assess the knowledge of mothers regarding childhood leukemia such as definition, signs and symptoms, diagnostic procedures, treatment modalities especially chemotherapy and its associated side effect such as nausea, vomiting, hair loss, fatigue, etc...

3- Reported-practice sheet: It contained 33 questions covering the care provided by the mothers for their children with leukemia in the diagnosis period and induction phase of chemotherapy.

Scoring system: For knowledge assessment sheet and reported practice sheet; each complete/ correct response took two scores, the incomplete one took one score and the wrong response or the not known/done one took zero. The total mothers' knowledge score was 64 score while it was 66 score for mothers' reported practice.

\section{Nursing instructions:}

In the current study, the nursing instructions considered all nursing activities or interventions, planned and designed by the research investigator after extensive review of related literature to be followed during the diagnosis period and induction phase of chemotherapy. The designed nursing instructions were provided to improve practice of mothers about dealing with diagnostic procedures and caring of side effects of chemotherapeutic agents e.g. nausea, vomiting, stomatitis, fatigue. The nursing instructions were presented in the form of educational materials such as illustrated Arabic booklet.

\section{Validity and reliability:}

The content of the data collection tools was submitted to five experts in the field of pediatric oncology from NCI, and pediatric nursing. Tools were examined for content coverage, clarity, relevance, applicability, wording, length, format, and overall appearance. Based on experts' comments and recommendations; minor modifications had been made such as rephrasing and rearrangements of some sentences. The internal consistency was measured to identify the extent to which the items of the tools measure the same concept and correlate with each other. Internal consistency estimates 
reliability by grouping questions in a questionnaire that measures the same concept. Cronbach's alpha coefficient was used to assess the internal consistency of the tool and its value was .0 .81 .

\section{Field work:}

An official permission to conduct the proposed study was obtained from the chairperson of the Pediatric Oncology Department in NCI. Mothers who met the selection criteria were invited to participate in the study. The purpose and the nature of study were explained to each mother individually. A formal written consent was obtained from each mother to get her acceptance as well as to gain her cooperation. Clear and simple explanations about the aim and nature of the study were discussed by the research investigator for each mother. The study was conducted on four phases; assessment, designing, implementation and evaluation phase. The assessment phase was included the assessment of the setting, assessment of required materials and assessing the required sample size. The designing phase was involved designing of nursing instructions materials e.g. illustrated Arabic booklet which designed and guided by assessment of knowledge and practice of mothers. Second: The extensive review of the related literature. Then, the pilot study was conducted. After the official permission is granted to proceed with the proposed study. Implementation and evaluation phase was initiated.

Mothers and their children who met the inclusion criteria were approached by the research investigator; personal data, history of child's diagnosis were collected by the developed tools from each mother and her child on individual bases. Assessment of mothers' knowledge and practice (pre-test) was conducted and taken from 25 to 30 minutes. The nursing instructions designed and planned to be followed during the diagnosis period and induction phase of chemotherapy was explained through 7 educational sessions on individual basis and sometimes for a group of mothers (4-5 mothers); aided by the using of illustrated Arabic booklet, and educational videos from medical sites.

The nursing instructions was provided orally and written for mothers at the diagnosis period in Pediatric Oncology Outpatient Clinic waiting area at NCI on two separate sessions (session I, II); duration of each one is about 60 minutes. Nursing instructions provided at this period was aimed to enrich mother's knowledge about leukemia especially ALL, signs and symptoms, requested diagnostic procedure and explain the role of mother during this period.
Other nursing instruction sessions was provided on five separate sessions (third to seventh session) at pediatric oncology 5 th floor inpatient department before and during the induction phase of chemotherapy; duration of each one is about 60 minutes. Nursing instructions provided at this period was aimed to guide mothers practices about care of their children during this critical period such as instructions about medications, care of signs and symptoms and dealing with side effects of chemotherapy e.g. fever, stomatitis, fatigue and weakness, etc. ... Finally, for evaluating the effect of provided nursing instructions, further assessment of mother's knowledge and practice was also carried out at the end of the induction phase of chemotherapy (posttest). Data collection was conducted over 11 month's period extending from May 2014 till April 2015.

\section{Pilot study:}

The pilot study was carried out on five mothers having children with ALL at Pediatric Oncology Outpatient Clinic in the NCI to assess the feasibility, objectivity, applicability, clarity, adequacy, and content validity of the study tools and time required to fulfill it and to determine possible problems in the methodological approach or instrument. The results of the pilot study were used to test the proposed statistical and data analysis methods. The tools were completed without difficulty, adding support to the validity of the instrument. Little modification was done e.g. rephrasing and rearrangements of some sentences. Mothers and their children involved in the pilot study were included in the main study sample.

\section{Administrative and ethical considerations:}

A primary approval was obtained from the Research Ethical Committee in the Faculty of Nursing, Cairo University, to approve the research. A written informed consent was obtained from the mothers of children after complete description of the purpose and nature of the study. Children and their mothers were informed that participation in the study is voluntary, that they have the right to withdraw from the study at any time, without giving any reason and without any effect on the care of their children. Confidentiality was assured to each child and his care giver overall the conducted study. After completion of data collection, the final approval was obtained from the Research Ethical Committee in the Faculty of Nursing, Cairo University.

\section{Statistical analysis:}

The collected data were, coded, categorized, tabulated, and analyzed using the Statistical Pack- 
age for the Social Science (SPSS 21.0). Descriptive data were expressed as mean and standard deviation. Qualitative data were expressed as frequency and percentage. Chi-square was used to detect the relation between mothers' knowledge and reported practice based on their selected personal variables of mothers and their children. Comparison of means was performed using paired-sample $t$-test to compare the total mean score of mothers' knowledge and reported practice before and after implementation of the designed nursing instructions. Correlation among variables was done using Pearson correlation coefficient. Level of significance at $p<0.05,0.001$ were used as the cut of value for statistical significance.

\section{Results}

Regarding to mothers' personal data, the results of the current study revealed that, the highest percentage of mothers (42\%) their age ranged from 30 to 35 years and $46 \%$ of them had basic and secondary school education. On the other hand, $28 \%$ of the mothers were can't read and write. The vast majority $(96 \%)$ of mothers were married. The maximum percentage of the mothers had 3 to 4 members in their family (Table 1). Fig. (1) illustrated that, $84 \%$ of the mothers were housewives and $16 \%$ of them were working outside home. Fig. (2) showed that, $60 \%$ of the mothers came from urban areas and $40 \%$ from rural areas.

Table (1): Percentage distribution of mothers' personal data $(n=50)$.

\begin{tabular}{lll}
\hline Mothers' personal data & $\mathrm{N}$ & $\%$ \\
\hline Age/year: & & \\
$17-24$ & 5 & 10 \\
$25-29$ & 10 & 20 \\
$30-34$ & 21 & 42 \\
$35-43$ & 9 & 18 \\
44 and more & 5 & 10 \\
Level of education: & & \\
Can't read and write & 14 & 28 \\
Can read and write & 6 & 12 \\
Basic and secondary school education & 23 & 46 \\
University graduate & 7 & 14 \\
Marital status: & \multicolumn{2}{|c}{} \\
Married & 48 & 96 \\
Widow & 2 & 4 \\
\hline
\end{tabular}

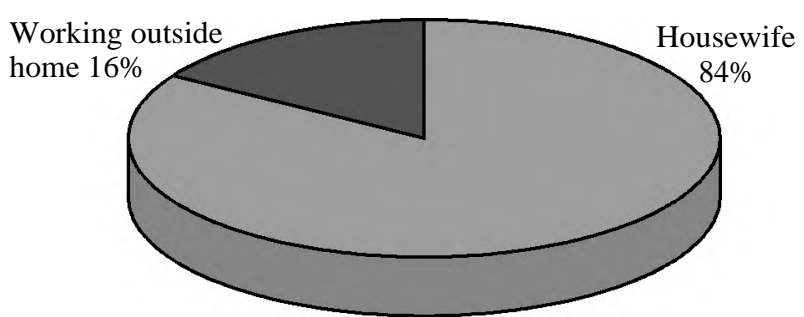

Fig. (1): Percentage distribution of mothers' occupation $(n=50)$.

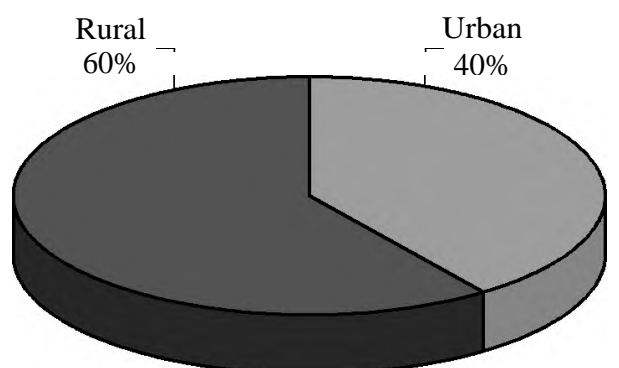

Fig. (2): Percentage distribution of mothers' place of residence $(n=50)$.

Concerning the personal characteristics of children with leukemia, Table (2) indicated that, more than half $(58 \%)$ of them their age ranged from 3 to 6 years. More than half $(54 \%)$ of them were females, ad $40 \%$ of them were ranked as the first child.

Table (2): Percentage distribution of children' personal characteristics $(n=50)$.

\begin{tabular}{lll}
\hline Children' characteristics & $\mathrm{N}$ & $\%$ \\
\hline Age/year: & & \\
$3-6$ & 29 & 58 \\
$7-10$ & 12 & 24 \\
$11-15$ & 9 & 18 \\
Rank within the family: & & \\
First & 20 & 40 \\
Middle & 17 & 34 \\
Last & 13 & 26 \\
\hline
\end{tabular}

Table (3) clarified that the majority of children ( $92 \% \& 86 \%$ respectively) suffer from fatigue and weakness as well as anorexia and loos of weight. In the same context, the highest percentages of them ( $80 \%$ \& $78 \%$ correspondingly) exposed to repeated infections and fever and suffer from joints and bone pain. On contrary, $86 \%$ of them not exposed to gum swelling and increased tendency to bleeding.

Table (3): Percentage distribution of symptoms that appeared on children when develop leukemia $(n=50)$.

\begin{tabular}{lllll}
\hline \multirow{2}{*}{ Symptoms } & \multicolumn{3}{c}{ Yes } & \multicolumn{2}{c}{ No } \\
\cline { 2 - 6 } & $\mathrm{N}$ & $\%$ & $\mathrm{~N}$ & $\%$ \\
\hline Fatigue and weakness & 46 & 92 & 4 & 8 \\
Repeated infections and fever & 40 & 80 & 10 & 20 \\
Anorexia and loos of weight & 43 & 86 & 7 & 14 \\
Joints and bone pain & 39 & 78 & 11 & 22 \\
Ease of bleeding and bruising & 14 & 28 & 36 & 72 \\
Night sweating & 35 & 70 & 15 & 30 \\
Enlarged and painful lymph nodes & 24 & 48 & 26 & 52 \\
Headache and vomiting & 21 & 42 & 29 & 58 \\
Red patches under skin & 20 & 40 & 30 & 60 \\
Gum swelling and increased tendency to bleeding & 7 & 14 & 43 & 86 \\
\hline
\end{tabular}


Regarding to mothers' knowledge, Table (4) indicated that, more than half $(58 \%)$ of mothers don't know the causes of childhood leukemia before receiving nursing instructions compared to $50 \%$ of them had complete knowledge about these causes after nursing instructions. Leukemia is an infectious disease as responded by $64 \%$ of mothers before implementation of nursing instructions, while, all of them $(100 \%)$ denied this claim. More than half (54\%) of mothers participated in the current study had incomplete knowledge about symptoms of leukemia. Contrariwise, after application of nursing instructions it was found that, $70 \%$ of them had complete knowledge about these symptoms. There were statistically significant differences between mothers' knowledge regarding causes, and symptoms of leukemia before and after receiving nursing instructions $(p<0.001)$.

Table (4): Comparison between mothers' knowledge about causes, and symptoms of childhood leukemia before and after nursing instructions $(n=50)$.

\begin{tabular}{lllll}
\hline Mothers' knowledge & \multicolumn{2}{c}{$\begin{array}{c}\text { Before } \\
\text { nursing } \\
\text { instructions }\end{array}$} & $\begin{array}{c}\text { After } \\
\text { nursing } \\
\text { instructions }\end{array}$
\end{tabular} $\mathrm{X}^{2} \quad p$

\begin{tabular}{|c|c|c|c|c|c|c|}
\hline \multicolumn{7}{|c|}{$\begin{array}{l}\text { Causes of childhood } \\
\text { leukemia: }\end{array}$} \\
\hline Complete & 3 & 6 & 25 & 50 & 37.222 & $.000 * *$ \\
\hline Incomplete & 18 & 36 & 21 & 42 & & \\
\hline Don't know & 29 & 58 & 4 & 8 & & \\
\hline \multicolumn{7}{|c|}{$\begin{array}{l}\text { Leukemia is an } \\
\text { infectious disease: }\end{array}$} \\
\hline Yes & 0 & 0 & 0 & 0 & 21.951 & $.000 * *$ \\
\hline No & 32 & 64 & 50 & 100 & & \\
\hline Don't know & 18 & 36 & 0 & 0 & & \\
\hline \multicolumn{7}{|c|}{$\begin{array}{l}\text { Symptoms of } \\
\text { childhood leukemia: }\end{array}$} \\
\hline Complete & 1 & 2 & 35 & 70 & 79.333 & $.000 * *$ \\
\hline Incomplete & 27 & 54 & 15 & 30 & & \\
\hline Don't know & 22 & 44 & 0 & 0 & & \\
\hline
\end{tabular}

In addition to (Table 5) clarified that $70 \%$ of the mothers answered that chemotherapy is the treatment of choice to manage most cases of leukemia this percentage increased to $100 \%$ after nursing instructions. More than half (58\%) of the mothers had incomplete knowledge about methods of chemotherapy administration before nursing instructions, nevertheless, $54 \%$ of them gained complete knowledge about this issue after application of nursing instructions. The majority ( $88 \%$ ) of the mothers had no knowledge about all types of leukemia are treated with one type of chemotherapy but after application of nursing instructions, $88 \%$ of them said no. There were statistically significant differences between mothers before and after nursing

instructions in aspect of methods and types of chemotherapy administration $(p<0.001)$.

Table (5): Comparison between mothers' knowledge about chemotherapy before and after nursing instructions $(\mathrm{n}=50)$.

\begin{tabular}{lllll}
\hline Mothers' knowledge & $\begin{array}{c}\text { Before } \\
\text { nursing } \\
\text { instructions }\end{array}$ & $\begin{array}{c}\text { After } \\
\text { nursing }\end{array}$ & instructions
\end{tabular} $\mathrm{X}^{2} \quad p$

The treatment of choice to

manage most cases of

leukemia is:

- Chemotherapy

- Radiotherapy

- Bone marrow

transplantation

- Don't know

35

$\begin{array}{ll}0 & 0\end{array}$

1007.269

0

$\begin{array}{ll}0 & 0\end{array}$

$30 \quad 0 \quad 0$

Methods of chemotherapy

administration:

- Complete

- Incomplete

- Don't know

0

29

$\begin{array}{ll}0 & 27\end{array}$

$58 \quad 23$

420

54

46

$45.164 .006 * *$

All types of leukemia are

treated with one type of

chemotherapy:

- Yes

- No

- Don't know

**: Significant at $p<0.001$.

Regarding to phases and side effects of chemotherapy before and after nursing instructions, Table (6) evident that all (100\%) of the mothers don't know the phases of chemotherapy, while $72 \%$ of them knew the phases after implementation of nursing instructions. Most of the mothers (98\%) don't know that chemotherapy affects cancer cells and healthy cells as well. Conversely, after nursing instructions, it was found that $72 \%$ of them replied that chemotherapy affects cancer cells, and healthy cells.

The same table illustrated that, $64 \%$ of the mothers had incomplete knowledge related to side effects of chemotherapy whereas, after getting nursing instructions, nearly two thirds $(66 \%)$ of them gained complete knowledge regarding this matter. All $(100 \%)$ of mothers in the current study don't know the timing of side effects of chemotherapy before nursing instructions. On the other hand, $72 \%$ of them had complete knowledge about this subject after nursing instructions. There were statistically significant differences between mothers before and after nursing instructions in respect of phases, side effects of chemotherapy and timing of side effects of chemotherapy $(p<0.001)$. 
Table (6): Comparison between mothers' knowledge about phases and side effects of chemotherapy before and after nursing instructions $(\mathrm{n}=50)$.

\begin{tabular}{llllll}
\hline Mothers' knowledge & $\begin{array}{c}\text { Before } \\
\text { nursing } \\
\text { instructions }\end{array}$ & $\begin{array}{c}\text { After } \\
\text { nursing } \\
\text { instructions }\end{array}$ & $\chi^{2}$ & $p$ \\
\cline { 2 - 4 } & $\mathrm{N}$ & $\%$ & $\mathrm{~N}$ & $\%$ & \\
\hline
\end{tabular}

Phases of chemotherapy:

- Complete

- Incomplete

- Don't know

$\begin{array}{lll}0 & 0 & 36\end{array}$

$72 \quad 16.279 \quad .003 * *$

22

6
Chemotherapy affects

cancer cells, and healthy

cells as well:

- Yes

- No

- Don't know

$1 \quad 2 \quad 36$

$\begin{array}{lll}1 & 0 & 3\end{array}$

$7260.175 .006^{* *}$

Side effects of

chemotherapy:

- Complete

- Incomplete

- Don't know

$\begin{array}{lll}0 & 0 & 33\end{array}$

$\begin{array}{lll}32 & 64 & 17\end{array}$

$18 \quad 36 \quad 0$

$66 \quad 62.082 \quad .000 * *$

34

0

Timing of side effects of

chemotherapy:

- After the first dose

-With the end of treatment

- Don't know

$0 \quad 0 \quad 38$

$7272.414 .000 * *$

**: Significant at $p<0.001$.

Table (7): Comparison between mothers' reported practice provided for children before, during and after chemotherapy session, and management of child's pain before and after nursing instructions $(n=50)$.

\begin{tabular}{llllll}
\hline & \multicolumn{2}{c}{$\begin{array}{c}\text { Before } \\
\text { nursing } \\
\text { Mothers' reported } \\
\text { practice }\end{array}$} & $\begin{array}{c}\text { After } \\
\text { nursing } \\
\text { instructions }\end{array}$ & $\begin{array}{l}2 \\
\text { instructions }\end{array}$ & $\chi^{2}$
\end{tabular}

\begin{tabular}{lllllll}
\hline $\begin{array}{l}\text { Measures should be done } \\
\text { before chemotherapy }\end{array}$ & & & & & & \\
session: & 0 & 0 & 31 & 62 & 71.90 & $.000 * *$ \\
$\quad$ Complete & 1 & 2 & 12 & 24 & & \\
$\quad$ Incomplete & 49 & 98 & 7 & 14 & & \\
Don't know & 49 & & & & &
\end{tabular}

Care provided for the

child during and after

chemotherapy session:

$\begin{array}{lllllll}\text { Complete } & 0 & 0 & 34 & 68 & 88.679 & .000 * * \\ \text { Incomplete } & 0 & 0 & 13 & 26 & & \\ \text { Don't know } & 50 & 100 & 3 & 6 & & \end{array}$

Precautions taken to

protect the child at home

after chemotherapy

session:

$\begin{array}{lllllll}\text { Complete } & 0 & 0 & 39 & 78 & 85.185 & .000^{* *} \\ \text { Incomplete } & 0 & 0 & 7 & 14 & & \\ \text { Don't know } & 50 & 100 & 4 & 8 & & \end{array}$

**: Significant at $p<0.001$.

As regards mothers' reported practice provided for their children with leukemia during induction phase of chemotherapy before and after nursing instructions, Table (7) proved that $98 \%$ and $100 \%$ respectively of them don't know the care should be provided for their children before and during chemotherapy session. But after implementation of nursing instructions it was found that $62 \%$ and $68 \%$ respectively of them can provide care for their children regarding these elements completely.

All mothers (100\%) don't know the precautions taken to protect the child at home after chemotherapy session, nevertheless, after application of nursing instructions, more than three quarters $(78 \%)$ of them knew these precautions. Statistically significant differences were detected between mothers before and after nursing instructions in respect of care provided for their children before, during and after chemotherapy sessions and during pain ( $p$ $<0.001)$.

Table (8) illustrated that before application of nursing instructions, the total mean score of mothers' knowledge regarding childhood leukemia and chemotherapy was $13.28 \pm 7.65$ increased to $48.6 \pm$ 10.52 after getting nursing instructions. A highly statistically significant difference was detected between the total mean score of mothers' knowledge before and after nursing instructions $(p<0.001)$.

Table (8): Comparison between total mean score of mothers' knowledge and reported practice about childhood leukemia and chemotherapy before and after nursing instructions $(\mathrm{n}=50)$.

\begin{tabular}{|c|c|c|c|c|c|}
\hline Variables & $\begin{array}{c}\text { Mothers' } \\
\text { knowledge } \\
\mathrm{M} \pm \mathrm{SD}\end{array}$ & $t$ & $p$ & $\begin{array}{l}\text { Mothers' } \\
\text { reported } \\
\text { practice } \\
\mathrm{M} \pm \mathrm{SD}\end{array}$ & $p$ \\
\hline $\begin{array}{l}\text { Before } \\
\text { nursing } \\
\text { instruction }\end{array}$ & $13.28 \pm 7.65$ & .641 & $.000 * *$ & $8.82 \pm 3.68$ & $-16.7 .000 * *$ \\
\hline $\begin{array}{l}\text { - After } \\
\text { nursing } \\
\text { instruction }\end{array}$ & $48.6 \pm 10.52$ & & & $38.88 \pm 13.2$ & \\
\hline
\end{tabular}

**: Significant at $p<0.001$.

Concerning the level of mothers' knowledge about childhood leukemia and chemotherapy, Table (9) proved that all $(100 \%)$ of the mothers had poor level of knowledge before receiving nursing instructions. Nevertheless, after nursing instructions, more than half $(52 \%)$ of them had good level of knowledge and $40 \%$ had average level of reported practice. Highly statistically significant difference was identified between the level of mothers' knowledge and reported practice before and after nursing instructions $(p<0.001)$.

The study results evident that there were highly statistically significant positive correlations between mothers' total mean score of knowledge and 
reported practice and their level of education $(r=$ $.547, p=<0.001 \& r=.412, p=<0.001$ respectively). A statistically significant positive correlation was detected between mothers' total mean score of reported practice and their occupation $(r=.333$, $p=<0.05)$. On the same line, there was highly sta- tistically significant positive correlation between mothers' total mean score of reported practice and their place of residence. On the other hand, there were no statistically significant correlations between mothers' total mean score of knowledge and practice and their age and marital status.

Table (9): Comparison between mothers' level of knowledge and reported practice regarding childhood leukemia and chemotherapy before and after nursing instructions $(n=50)$.

\begin{tabular}{|c|c|c|c|c|c|c|c|c|c|c|c|c|}
\hline \multirow{3}{*}{ Variables } & \multicolumn{6}{|c|}{ Mothers' knowledge } & \multicolumn{6}{|c|}{ Mothers' practies } \\
\hline & \multicolumn{2}{|c|}{$\begin{array}{c}\text { Before } \\
\text { nursing } \\
\text { instruction }\end{array}$} & \multicolumn{2}{|c|}{$\begin{array}{l}\text { After } \\
\text { nursing } \\
\text { instruction }\end{array}$} & \multirow[t]{2}{*}{$\chi^{2}$} & \multirow[t]{2}{*}{$p$} & \multicolumn{2}{|c|}{$\begin{array}{l}\text { Before } \\
\text { nursing } \\
\text { instruction }\end{array}$} & \multicolumn{2}{|c|}{$\begin{array}{c}\text { After } \\
\text { nursing } \\
\text { instruction }\end{array}$} & \multirow[t]{2}{*}{$\chi^{2}$} & \multirow[t]{2}{*}{$p$} \\
\hline & $\mathrm{N}$ & $\%$ & $\mathrm{~N}$ & $\%$ & & & $\mathrm{~N}$ & $\%$ & $\mathrm{~N}$ & $\%$ & & \\
\hline Poor & 50 & 100 & 3 & 6 & 46.08 & $.000 * *$ & 50 & 100 & 19 & 38 & 46.5 & $.000 * *$ \\
\hline Average & 0 & 0 & 21 & 42 & & & 0 & 0 & 20 & 40 & & \\
\hline Good & 0 & 0 & 26 & 52 & & & 0 & 0 & 11 & 22 & & \\
\hline
\end{tabular}

**: Significant at $p<0.001$.

\section{Discussion}

The results of the current study revealed that the highest percentage of mothers their age ranged from 30 to 35 years and had basic and secondary school education. The vast majority of mothers were married and housewives. Similarly, in a recent study conducted by [10] to assess the correlation between coping strategies and the health related quality of life of 299 mothers whose children are suffering from ALL. The study summarized that the mothers' age ranged from 23 to 54 years old and the mean age was 37.7 years. The majority was married $(94.5 \%)$, and with the highest education achieved was minimum of secondary education level (78.8\%), and about half of the respondents were employed.

As shown in the current study the highest percentage of mothers came from urban areas and two fifths of them were from rural areas. This result could be related to the NCI serves care for children with various types of cancer in the Cairo metropolitan and surrounding rural and semi-urban areas. On the same context, [11] documented that the rural population was $57 \%$ of the total population all over the world. In the same line, [12] documented that in Egypt, urban population was $43.1 \%$ of the total population and the rate of urbanization was $1.68 \%$ annual rate of change. Besides, [13] reported that $68 \%$ of the urban places had more incidence of childhood leukemia in India.

Concerning the characteristics of children with ALL, the results of the current study documented that more than half of children were females and their age ranged from 3 to 6 years. These results were contradicted with [10] who found that $60.8 \%$ of the children who participated in the study were males and their age ranged from 5 months to 18 years. Furthermore, [14] studied the gender differences in incidence rates of childhood B-precursor acute lymphocytic leukemia in Mississippi in the United States, the study concluded that childhood leukemia is significantly more prevalent in boys. An Egyptian study held by [15] to identify the health-related quality of life profile among 67 Egyptian pediatric cancer patients aged 8-12 years summarized that $64.2 \%$ of children were males. Children with hematological malignancies represented $70.1 \%$ versus $29.9 \%$ with solid tumors, with the highest proportion for ALL (52.2\%). On the same perspective [16] evaluated the outcome of childhood ALL in 52 Egyptian children aged 1-17 years. The mean age at diagnosis was $5.9+3.3$ years, male/female ratio of 1.6:1.

American Cancer Society [17] documented that many signs and symptoms of childhood leukemia happen when leukemia cells crowd out normal cells. Common symptoms include fatigue, pale skin, infections and fever, easy bleeding or bruising, shortness of breath, bone or joint pain, loss of appetite, loss of weight, abdominal distention and sometimes headaches, seizures, balance problems, and vomiting. The results of the current study were in accordance to the above mentioned empirical evidences and demonstrated that the majority of children suffer from fatigue and weakness as well as anorexia and loss of weight. In the same context, the highest percentages of them exposed to repeated infections and fever and suffer from joints and bone pain. 
Moreover, empirical evidence and previously cited literature by [18] reported that, the conventional signs of anemia, thrombocytopenia, hepatosplenomegaly or lymphadenopathy are highly suspicious of leukemia but initial symptoms are often nonspecific and vague and are very similar to common, self-limiting viral illness. These symptoms include general malaise, fatigue and lethargy; prolonged or recurrent episodes of fever; failure to thrive; shortness of breath and/or reduced exercise tolerance; bleeding diathesis, particularly causing epistaxis, bleeding gums and/or easy bruising and repeated or severe common childhood infections.

In relation to mothers' knowledge about childhood leukemia and chemotherapy before and after nursing instructions, the current study results revealed that before receiving the nursing instructions the highest percentages of mothers don't know nor had incomplete knowledge about what are leukemia and its prevalence; causes and symptoms of leukemia. Also had incomplete knowledge related to chemotherapy and its side effects. The overall level of mothers' knowledge about childhood leukemia and chemotherapy was poor. These results indicate the mothers' need for information and instructions about leukemia. The results indicate to all of us in the health team members that care must be taken to inform mothers about pediatric cancer in general and childhood leukemia in particular.

The current study results were in accordance with [19] in a cross-sectional study on 300 mothers to assess their educational needs about etiology of children's leukemia. The results showed that most of mothers had moderate or weak knowledge; only $31.33 \%$ of mothers had appropriate knowledge in etiology of leukemia. In an Egyptian study held by [20] to assess knowledge and home practices of 192 caregivers having children with leukemia attending NCI, Cairo University, concluded that more than two thirds of caregivers had partially satisfactory knowledge concerning care of their children with leukemia.

The same explanation was reported by [21] study to knowledge on leukemia, the stress and coping strategies among 40 mothers with leukemic children undergoing treatment in a selected cancer institute, in India. It was found that most of the mothers' knowledge is below the average score; nonetheless they have a high interest in learning more about it. Recently, [22] assessed the home care management for caregiver's having leukemic adolescent patient in Erbil city. The study showed the majority of caregiver had deficit knowledge regarding childhood leukemia. In conclusion, the majority of the mothers who participated in the current study after receiving the nursing instructions had complete knowledge regarding to definition, causes, types, symptoms of childhood leukemia. Also the highest percentages of them had complete knowledge pertinent bone marrow aspiration, chemotherapy, phases and side effects of chemotherapy and other knowledge matters about childhood leukemia. Hence, these results denoting the effectiveness of the nursing instructions in improving and enhancing mothers' knowledge related to the above mentioned issues.

The total mean score of mothers' knowledge regarding childhood leukemia and chemotherapy was dramatically increased after getting nursing instructions. A highly statistically significant difference was detected between the total mean score of mothers' knowledge before and after nursing instructions. The overall level of mothers' knowledge after implementation of the nursing instructions was good among more than half of the mothers. These findings support the first current study hypothesis.

In a previous Egyptian study by [23] found that the parents' knowledge as regards childhood leukemia, risk factors, chemotherapy and bone marrow aspiration was significantly improved after the implementation of the psycho-educational program. The study results proved that highly statistically significant relations between parents knowledge regarding leukemic disease characteristic, diagnosis, symptom, treatment, side effects of chemotherapy before and after intervention. The current study results also were in accordance with [24] who assessed the role of enhancement of maternal knowledge and practice in improving health status of children with cancer. The study was conducted in Oncology Institute of Tanta and Specialized Pediatric Hospital of Benha City, Egypt. In the light of the study findings, it was found that the developed educational intervention lead led to significant improvements in mothers' knowledge regarding care of their children with cancer.

Concerning mothers' reported practice provided for their children with leukemia during diagnosis stage and induction phase of chemotherapy before nursing instructions, the current study results highlighted that the majority of the mothers not able to provide care for their children before, during or after the chemotherapy sessions. Mothers reported incomplete care for their children as regards side 
effects of chemotherapy. The highest percentages of them did not oriented by the precautions taken to protect the child at home after chemotherapy session. Unfortunately, all mothers had poor level of reported practice as regards care of their children undergoing chemotherapy. This could have a negative impact on their ability to provide proper care for their children. Providentially, the total mean scores of the mothers' reported practice during the diagnosis stage and induction phase of chemotherapy after receiving the nursing instructions were significantly higher than in the pretest. These results support the second study hypothesis. Additionally, the highest percentage of the mothers had average level of reported practice as regards the care of their children during the diagnosis stage, these results signifying the effectives of the nursing instructions in improving mothers' practice.

The same results were obtained by [25] who assessed mothers' knowledge and practices regarding care of their children suffering from acute leukemia undergoing chemotherapy, establish and implement a health educational program for 53 mothers based on their needs. The findings showed that after the program implementation there was a significant improvement of mothers' practices regarding care of their acute leukemic children undergoing chemotherapy. Similarly, [24] found that the mean score of mothers' practice regarding the care provided for their children with cancer was improved post intervention compared by pre intervention $(p<0.05)$. On the same perspective, [20] found that more than two thirds of parents had partially satisfactory practice scores concerning home care, dealing with disease and side effects of treatments among their children with leukemia. The authors recommended development of a health education programs tailored to improve knowledge and home care practices of caregivers having children with leukemia.

Likewise, empirical evidence and previously cited research by [22] concluded that, there were highly statistically significant relations between parents' caregiver's practices regarding caring child with leukemia disease before and after program. It was observed in, using soft toothbrush, fluid intake, dealing with nausea, exercise, social activity and intake of tea and café $(p>0.001)$. In the same line, [21] found that the caregivers who are having adolescent leukemia patients had low practices regarding home care management and recommended providing information and guidance to caregivers through health educational intervention regarding home care management for leukemic adolescent.

\section{Conclusion:}

The current study concluded that the designed nursing instructions were effective in improving mothers' total mean score of knowledge and reported practice regarding care of their children with leukemia undergoing chemotherapy than before.

\section{Recommendations:}

Based on the results of the current study, the following recommendations are suggested:

- Integration of the designed nursing instructions for mothers of children with leukemia undergoing chemotherapy in Pediatric Oncology Units; it would provide a framework for mothers' role for their children with leukemia.

- Health education sessions and awareness campaigns about childhood leukemia and how mothers to deal and manage their children especially in rural remote areas are mandatory.

- A multidisciplinary team consisting of pediatric oncology clinicians, rehabilitation therapist, pediatric oncology nurses, dietitian, life coaching and social workers should be involved in preparation and implementation of the nursing instructions to provide holistic care for children with leukemia and their families.

\section{Recommendations for further researches:}

- Longitudinal study is necessary to evaluate the impact of the nursing instructions provided for mothers on QOL and health status of their children with leukemia.

- Replication of this study is warranted, this would enhance opportunities to generalize the findings to other types of pediatric oncological disorders, and other pediatric oncology clinical settings.

\section{References}

1- World Healt Rganization: Cancer. Available at www.who. int/cancer/en, Accessed on 3/2018, 2017.

2- GUPTA S., HOWARD S., HUNGER S., ANTILLON F., METZGER M., HARIF M. and RODRIGUEZ-GALINDO C.: "Treating Childhood Cancers in Low-and MiddleIncome Countries". In: Disease Control Priorities: Available at www.ncbi.nlm.nih.gov.accessed on 20/12/2017, 2015.

3- National Cancer Institute (NCI), United States of America: Available at www.natureindex.com. Accessed on 3/2018, 2017.

4- RIFKY E.A., SHERIF L., MOHAMED N., GHARIB A. and SHAWKY H.: Acute lymphoblastic leukemia: Are Egyptian children adherent to maintenance therapy? Journal of Cancer Research and Therapeutics: 1-5, 2015. 
5- BHOJWANI D., YANG J. and PUI C.: Biology of childhood acute lymphoblastic leukemia. Pediatric Clinics of North America; 62 (1): 47-60, 2015.

6- American Cancer Society: Chemotherapy. Available at www.cancer.org. Accessed in September 2017, 2016.

7- TARIMAN D., MEHMETI E., SPWAN N., McCARTER S., BISHOP-ROYSE J., GARCIA I., HARTLE L. and SZUBSKI K.: Oncology nursing and shared decision making for cancer treatment. Clinical Journal of Oncology Nursing, 20: 5: 560-3, 2016.

8- EL-HEFNAWY M.I., EBEID E.N., KHALID W.Z. and IBRAHIM D.M.: Pediatric Acute Lymphoblastic Leukemia at Nasser institute: Treatment outcome and Prognostic Factor. National Cancer Institute, Cairo University. P.p 1-132, 2013.

9- MOHRAM A.H., KAMEL A., ABOU EL-NAGA S. and EBEID E.: Treatment Plan for Newly Diagnosed Pediatric Patients with Low Risk Acute Lymphoblastic Leukemia at NCI. Cairo University. p.p. 5-224, 2010.

10- SUTAN R., AL-SAIDI N., LATIFF Z. and IBRAHIM H.: Coping strategies among parents of children with acute lymphoblastic leukemia. Health Journal, 9: 987-99, 2017.

11- United Nations Educational,Scientific and Cultural Organization [UNESCO] Institute of Statistics http://uis.unesco. . org/en/country/eg?theme=education-and-literacy Ministry of Education, Statistical Yearbook 2014-2015 Accessed in $16 / 10 / 2017$.

12- Egypt Demographic Profile: Available www.indexmundi. com/egypt/demographicsjrofile.html and accessed in 16/10/2017, 2015.

13- GEETHA C.: Knowledge on leukemia, the stress and coping strategies of mothers with leukemic children undergoing treatment in a selected cancer institute. International Journal of Recent Scientific Research, 6 (5): 4192-6, 2015.

14- FORSYTHE A., BRELAND T., MAJUMDAR S., ELKIN T., JOHNSON D. and MEGASON G.: Gender differences in incidence rates of childhood B-precursor acute lymphocytic leukemia in Mississippi Journal of Pediatric Oncology Nursing, 27 (3): 164-7, 2010.

15- FAWZY M., SALEH M., El-WAKIL M., MONIR Z. and ELTAHLAWY E.: Quality of life in Egyptian children with cancer. Journal of Cancer Therapy, 4: 1256-61, 2013.
16- TANTAWY A., El-RASHIDY F., RAGAB I., RAMADAN O. and El-GAAFARY M.: Outcome of childhood acute Lymphoblastic leukemia in Egyptian children: A challenge for limited health resource countries. Journal of Hematology, 18 (4), 2013.

17- American Cancer Society: What Are the Key Statistics for Childhood Leukemia? Available at www.cancer.org/ cancer/leukemia-in-children. Accessed on 15/1/2018, 2017.

18- TIDY D.: Childhood leukemia. Available at www.patient. info/doctor. Accessed on 12/12/2017, 2016.

19- SEDIGHEH S., MITRA G. and FARIBA F.: Mother's educational needs about etiology of children's leukemia. International Journal of Nursing Care, 1 (1): 73-6, 2013.

20- El-SAWY M., ISMAIL G. and MAGDY H.: Knowledge and home practices of caregivers having children with leukemia attending National Cancer Institute Cairo University. Medical Journal of Cairo University, 81 (1): 6018, 2013.

21- GEETHA C.: Knowledge on leukemia, the stress and coping strategies of mothers with leukemic children undergoing treatment in a selected cancer institute. International Journal of Recent Scientific Research, 6 (5): 4192-6, 2015.

22- HASAN S., HUSSIEN K. and ALANI M.: Assessment of home care management for caregiver's having leukemic adolescent patient in Erbil city. Available at www.iasj.net. Accessed on 30/12/2017, 2017.

23- MAHMOUD S. and ABD EL-AZIZ N.: Effect of psychoeducational training program for parent's having child with leukemia on their experience and psychological wellbeing. Journal of Education and Practice, 6 (12), 2015.

24- EL-SAYED E. and MAHMOUD F.: Outcome of enhancement of maternal knowledge and practice on health status of their children with cancer. Journal of American Science, 8 (3): 322-33, 2012.

25- GIRGIS N., AHMAD S. and MOHAMED M.: Mothers' care of children suffering from acute leukemia undergoing chemotherapy at home in Benha City. Unpublished Master Thesis, 2009. 


\section{تآثير إرشادات تمريضية على معلومات وممارسات آمهات الآطفال المصابين بسرطان الدم الخاضعين للعلاج الكيماوى}

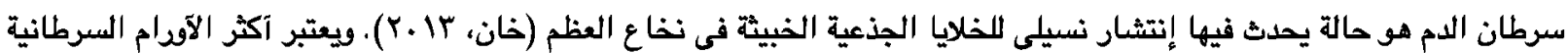

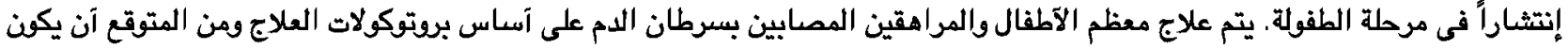

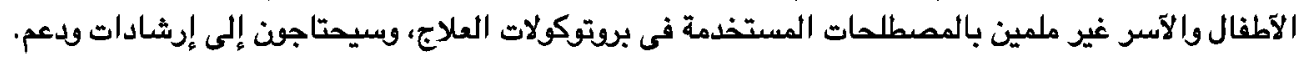

والهلف من الدراسة الحالية هو تقييم تآثير إرشادات تمريضية على معلومات وممارسات آمهات الآطفال المصابين بسرطان الدم الخاضعين اللعلاج الكيميائى.

تم إستخدام بحث شبه تجريبى حيث إستخدمت مجموعة واحدة في المرحلة القبلية والبعدية للإختبار للتفيذ الدراسة الحالية وآجريت الدراسة الداسة

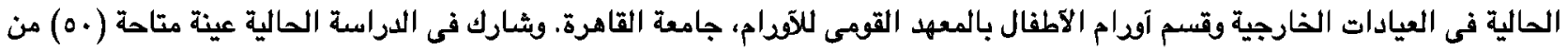

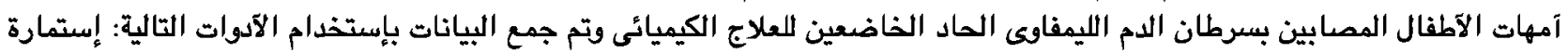

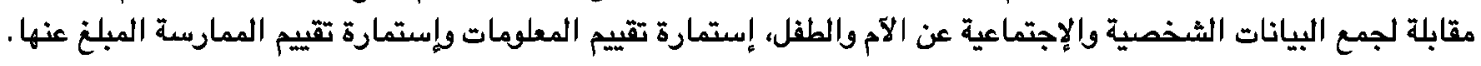
وخلصت الدراسة الهالية آن الإرشادات التمريضية المصممة كانت فعالة فى حصول الآمهات على متوسط درجات عالى الماتى فى المعلومات

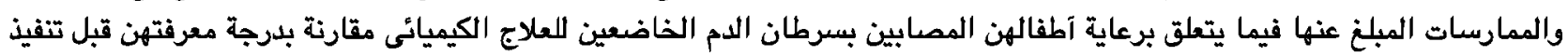
الإرشادات التمريضية.

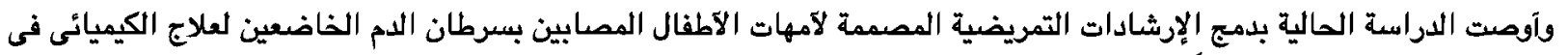

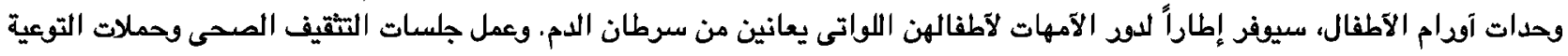

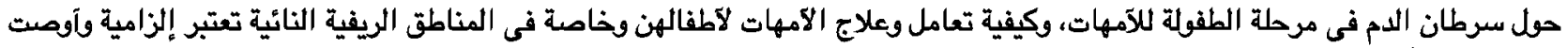

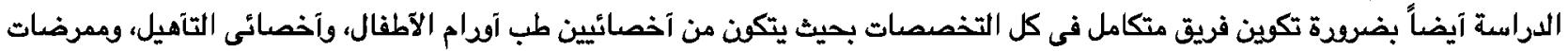

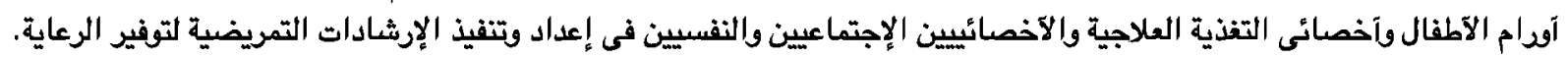

